Controversies in Obstetrics and Gynecology

University of Iowa Ob/Gyn Postgraduate Conference

October 28, 2011

Hotel Vetro, Iowa City, IA 52240

\title{
The menopause mess
}

\author{
Susan R. Johnson, MD, MS ${ }^{1,2}$
}

Our beliefs about menopause have been challenged by a series of randomized clinical trials, including the Women's Health Initiative (WHI), which have contradicted the results of observational studies which suggested hormone treatment as a "prevent all" for coronary heart disease, as well as several other common chronic diseases.

WHI has shown that estrogen plus progestin $(E+P)$ has a different risk profile than estrogen only. Women in the study (who begin E+P at least 5 years after the final period) had increased risk for breast cancer, stroke, coronary heart disease, and pulmonary embolism. Follow up analyses have shown that the risk for breast cancer declines, and returns to baseline within 2 years of discontinuing E+P. Estrogen only, on the other hand, appears not to increase the risks of either heart disease or breast cancer, and there is some evidence that if started early in the menopause heart disease risk may be decreased.

The message, based on the $\mathrm{WHI}$ analyses to date, remains the same: while hormone treatment is the most effective way to treat vasomotor symptoms, its use for prevention of chronic disease in women over 60 is not recommended. ${ }^{1}$ Because our understanding of the risks and benefits of hormone treatment remains a work in progress, clinicians should monitor future research. Two resources are the North American Menopause Society (NAMS)(http://www.menopause.org/), especially the position statements on menopause treatments, and the $\mathrm{WHI}$ (http://www.whi.org/), which includes summaries of new findings.

In the last decade we have also learned more about the menopause transition, the phase in which women move from reproductive age ovarian functioning to the final menstrual period. The Study of Women's Health Across the Nation (SWAN), is in its 11th year of data collection from a multi-ethnic cohort of over 3,000 women who were in their early 40's at the time the study began. SWAN seeks to better characterize the hormonal and symptom patterns of the transition, find a marker that will predict the final menstrual period, and determine factors that predict healthy aging.

${ }^{1}$ Department of Obstetrics and Gynecology, The University of lowa, lowa City, IA, 52240, ${ }^{2}$ Department of Epidemiology, The University of lowa, lowa City, IA 52240

Please cite this paper as: Johnson SR. The menopause mess. Proc Obstet Gynecol. 2011 November;2(2):Article 17 [ 2 p.]. Available from: http://ir.uiowa.edu/pog/. Free full text article.

Corresponding author: Susan R. Johnson, Department of Obstetrics \& Gynecology, University of lowa, 51242 PFP, 200 Hawkins Drive, lowa City, IA, 52242. Telephone (319)335-3608, susan-johnson@uiowa.edu 
Several findings are of interest to clinicians. Vasomotor symptoms commonly begin in the early transition, when women are still having regular menstrual periods; the rate of hot flashes doubles in the late transition and remains at the same level into the postmenopause. For a significant minority, hot flashes continue at least into the 60's. Depressive symptoms have been shown in other studies to increase during the menopause transition. SWAN showed, for the first time, that there is also an increase in the diagnosis of major depressive disorder at that time. ${ }^{2}$ SWAN has confirmed a decline in sexual desire beginning with the early transition. Cognitive function appears to be temporarily affected by the transition. Individuals taking cognitive tests repeatedly over time usually demonstrate a steady rate of improvement. Women in the transition demonstrate a slower rate of improvement, which then reverts to the normal rate in the post menopause. ${ }^{3}$ Finally, SWAN has found an increase in occasional urinary incontinence during this phase. ${ }^{4}$

\section{References}

1. North American Menopause Society. Estrogen and progestogen use in postmenopausal women: 2010 position statement of The North American Menopause Society. Menopause. 2010 Mar;17(2):242-55.

(http://www.menopause.org/PSht10.pdf)

2. Bromberger JT, Kravitz HM, Chang YF, Cyranowski JM, Brown C, Matthews KA. Major depression during and after the menopausal transition: Study of Women's Health Across the Nation (SWAN). Psychol Med. 2011 Sep;41(9):1879-88. Epub 2011 Feb 9. Erratum in: Psychol Med.2011 Oct;41(10):2238.

3. Greendale GA, Wight RG, Huang MH, Avis $N$, Gold EB, Joffe $H$, Seeman $T$, Vuge M, Karlamangla AS. Menopauseassociated symptoms and cognitive performance: results from the study of women's health across the nation. Am J Epidemiol. 2010 Jun 1;171(11):1214-24. Epub 2010 May 4.

4. Waetjen LE, Ye J, Feng WY, Johnson WO, Greendale GA, Sampselle CM, Sternfield B, Harlow SD, Gold EB; Study of Women's Health Across the Nation (SWAN). Association between menopausal transition stages and developing urinary incontinence. Obstet Gynecol. 2009 Nov;114(5):989-98. 